\title{
Interactive comment on "Tidal and seasonal forcing of dissolved nutrient fluxes in reef communities" by Renee K. Gruber et al.
}

\section{Anonymous Referee \#3}

Received and published: 16 January 2019

The study reports results from measurements of dissolved nitrogen and phosphorus fluxes in a tide-dominated reef. The fluxes were estimated using a one-dimensional control volume method, i.e. nutrient concentrations were measured on the reef platform at two points along the flow path of the tidal currents, and from the concentrations changes occurring between the two points, fluxes were estimated. The measurements suggest a release of nitrate, while fluxes of $\mathrm{NH} 4+$ and DIP varied between net uptake and release.

The results are interesting and produce new insights into the functioning of tidedominated reefs. A few points need clarification and revision:

This is a subtropical environment with healthy seagrass and coral cover. Nutrients in the water column are low and it is surprising that the reef platform with seagrass and 
healthy coral releases nitrate during low tide. Assuming that during the low water phase photosynthesis of vascular and unicellular plants reaches a maximum, one would expect nutrient uptake of the benthic community resulting in a net in uptake. Tidal current vector fields previously published by the authors for this study site (Lowe et al. 2015) revealed that the tidal water in and outflow is not symmetrical, resulting in a residual current entering the reef at its southeastern edge and leaving at its northeastern edge. These residual currents include flows parallel to the reef, which may cause that the two sampling stations measure some waters that took different pathways over the reef platform. It is conceivable that the residual currents transport water with different nutrient concentrations to the two measuring stations and that the observed difference in nitrate concentration between the two stations is a function of the pathways of the residual currents. The reef lagoon appears to be lined by mangrove forest and the seagrass community accumulates organic-rich sediments. The mixed zone between seagrass and coral has pockets of sediment and a porous structure. Could release of fluid from the sediments and the porous structure of the mixed zone explain the nutrient increase during decreasing water level as the path of the residual currents is along the mixed zone? This should be clarified.

The tidal range exceeding $8 \mathrm{~m}$ is unusual. This is not a typical scenario, which needs to be considered and pointed out when generalizing the results.

Minor comments.

P1L9 a "forcing" is not a "regime", please rephrase.

P1L25 "Reef waters have carbon concentrations that are orders of magnitude greater than nitrogen $(\mathrm{N})$ and phosphorus $(\mathrm{P})$ ". If a ratio close to Redfield is applicable here, $\mathrm{C}$ concentrations order(s) magnitudes higher than those of the nutrients can be expected. Benthic communities would not be nutrient limited. If carbon is way higher, please rephrase.

P2L10 "labile dissolved inorganic species". "Labile" here seems the wrong word as

Printer-friendly version

Discussion paper 
some of these inorganic species can be very stable in the marine environment.

P216 "turbulent transport" should be added to the list of the controls of nutrient transfer

P4L8 "reef benthos, which represent the net uptake or release of nutrients". Please add information on nutrient uptake/release of water column organisms

P4L32 "All nutrient concentrations presented are the mean of duplicate samples" why didn't you take triplicate samples, which would have allowed calculation of standard deviation, opening up other options for statistical analysis?

P5L8 How large is the error introduced by using depth-averaged current velocity instead

P11L8 If the coral zone is $\sim 20 \%$ more productive than the seagrass zone (Gruber et al., 2017), one would expect an increasing $N$ consumption during decreasing water level as light intensity at the reef surface increases, with higher $\mathrm{N}$ demands in the coral zone. The results suggest the opposite, how is this explained?

P11L20 "In a simplified wave-driven reef, offshore (oceanic) water moves from reef crest to back reef roughly unidirectionally. Thus, benthic communities are subjected to the physico-chemical water properties present in offshore waters modified by the communities 'upstream' of them." This should be explained in more detail, as water transported into the reef also has to leave the reef, irrespective of the transport process. This release may traverse the communities that contacted this water before as in the tidal dominated reef.

Interactive comment on Biogeosciences Discuss., https://doi.org/10.5194/bg-2018-413, 2018. 